\title{
Ontogeny of swimming speed, schooling behaviour and jellyfish avoidance by Japanese anchovy Engraulis japonicus.
}

\author{
AUTHOR(S):
}

Masuda, $\mathrm{R}$

\section{CITATION:}

Masuda, R. Ontogeny of swimming speed, schooling behaviour and jellyfish avoidance by Japanese anchovy Engraulis japonicus.. Journal of fish biology 2011, 78(5): 1323-1335

\section{ISSUE DATE:}

2011-04-04

URL:

http://hdl.handle.net/2433/197318

\section{RIGHT:}

This is the peer reviewed version of the following article: Masuda, R. (2011), Ontogeny of swimming speed, schooling behaviour and jellyfish avoidance by Japanese anchovy Engraulis japonicus. Journal of Fish Biology, 78: 1323-1335, which has been published in final form at http://dx.doi.org/10.1111/j.1095-8649.2011.02936.x; この論文は出版社版であ りません。引用の際には出版社版をご確認ご利用ください。;This is not the published version. Please cite only the published version. 
1 Ontogeny of swimming speed, schooling behaviour and jellyfish avoidance by

2 Japanese anchovy Engraulis japonicus

3

4 R. MASUDA

5 Maizuru Fisheries Research Station, Kyoto University, Nagahama, Maizuru, Kyoto

6 625-0086, Japan

7

8 Running headline:

9 Ontogeny of anti-predator behavior in anchovy

10

11

12

13

14

15

16

17

18

19

20 Tel.: +81 77362 9063; fax: +81 77362 5513; email: reiji@kais.kyoto-u.ac.jp 
21 The ontogeny of swimming speed, schooling behaviour and jellyfish avoidance was

22 studied in hatchery-reared Japanese anchovy Engraulis japonicus to compare its life

23 history strategy with two other common pelagic fishes, jack mackerel Trachurus 24 japonicus and chub mackerel Scomber japonicus. Cruise swimming speed of anchovy

25 increased allometrically from 1.4 to 3.9 folds of standard length per second $\left(L_{\mathrm{S} \mathrm{S}}{ }^{-1}\right)$

26 during the course from early larval to metamorphosing stage. Burst swimming speed

27 also increased from 6.1 to $28 \mathrm{Ls} \mathrm{s}^{-1}$ in these stages. Cruise speed was inferior to that of

28 chub mackerel, as was burst speed to that of jack mackerel. Anchovy larvae were highly

29 vulnerable to predation by moon jellyfish Aurelia aurita and were readily eaten until

30 they reached $23 \mathrm{~mm} L_{\mathrm{S}}$, but not at $26 \mathrm{~mm} L_{\mathrm{s}}$. Schooling behavior (indicated by parallel

31 swimming) started at about $17 \mathrm{~mm} L_{\mathrm{S}}$. Average distance to the nearest neighbour was

32 shorter than values reported in other pelagic fishes. The relatively low predator

33 avoidance capability of Japanese anchovy may be compensated for by their transparent

34 and thus less conspicuous body, in addition to their early maturation and high fecundity.

36 Key words: Aurelia aurita; behavioural ontogeny; Engraulidae; population dynamics; 
The world's largest fisheries have largely depended on clupeoids such as sardine

41 Sardinops spp., herring Clupea spp. and anchovy Engraulis spp. (Hunter, 1980), among which anchovy are now probably the most dominant in many temperate areas. Periods of increased anchovy populations coincide with the declines of sardine populations off

44 Japan, California, Peru and Chile (Chavez et al., 2003). In the case of Japanese coastal waters, three major pelagic fishes, i.e., chub mackerel Scomber japonicus Houttuyn,

46 jack mackerel Trachurus japonicus (Temminck \& Schlegel), and Japanese anchovy Engraulis japonicus (Houttuyn), filled the empty niche resulting from the collapse of sardine Sardinops melanostictus (Temminck \& Schlegel) populations in the late 1980s. Dominance of one or two of these species occurs at c. 10-year intervals (Matsuda et al., 1991). Takasuka et al. (2008) studied the optimum spawning temperature of these fishes and found that Sardinops melanostictus and Scomber japonicus are stenothermal species with peak spawning at $16^{\circ} \mathrm{C}$ and $18^{\circ} \mathrm{C}$, respectively, whereas Trachurus japonicus and Engraulis japonicus are eurythermal with optimum spawning at $c .22^{\circ}$ C. This is coincident with the theory that fluctuations in pelagic fish populations are governed by global climatic change, the so-called "regime shift theory" (Kawasaki, 1992). Yet at each stage of population replacement, it is still not clear what would be the direct cause

57 of mortality leading to the competitive advantage for any one species. It is necessary to

58 elucidate which species will benefit from certain environmental conditions in order to better understand this cyclic pattern of population dynamics. 
On the other hand, the population of anchovy Engraulis encrasicolus (L.) in the

61 Black Sea has been seriously depleted over the past two decades in part due to predation by a gelatinous predator, an alien ctenophore, Mnemiopsis leidyi (Agassiz), that invaded

63 in the 1980s (Shiganova, 1998). Castro et al. (2000) also found an apparent inverse

64 relationship between the anchovy Engraulis ringens Jenyns larval density and

65 gelatinous predators (medusae, ctenophores and siphonophores) off Chile. Because

66 recently jellyfish blooms have become ubiquitous phenomena (Purcell et al., 2007), anchovy and other pelagic fish populations may decline due to the increased predation and competition.

Ecological aspects of pelagic fishes have been intensively studied by using otolith analysis of wild collected specimens (e.g. Takahashi \& Watanabe, 2005; Takasuka et al., 2007). Survival in the wild, however, is the outcome of the combination of predation pressure and growth, both dependent on temperature and other environmental factors. However, an experimental approach using hatchery-reared fish may allow insights into differences in biological performance such as growth and behavior, as have been conducted on Atlantic herring Clupea harengus L. (Hunter, 1972), northern anchovy Engraulis mordax Girard (Blaxter, 1985) and red drum Sciaenops ocellatus (L.) (Fuiman et al., 1999).

The goal of the present work was to collect basic information related to the ontogeny of anti-predator behaviour such as swimming speed, responsiveness, jellyfish avoidance and initiation of schooling behaviour in Engraulis japonicus. Masuda (2006) 
82 grower with a faster cruise swimming speed compared to Trachurus japonicus whereas

83 T. japonicus has a fast burst swimming speed and has a high avoidance capability from moon jellyfish Aurelia aurita (L.). In the present work, equivalent data for E. japonicus were collected to conduct interspecific comparisons among these three species.

86

MATERIALS AND METHODS

88

HUSBANDRY OF BROODSTOCK AND HATCHERY PRODUCTION

Candidates of broodstock were obtained at a commercial set net operated by local fishermen in Tai, Maizuru, Kyoto ( $35^{\circ} 56^{\prime}$ N, $135^{\circ} 45^{\prime}$ E) on 15 May 2007. About 200 adult E. japonicus were collected from the catch, kept in two 70 l-containers, transported to the Maizuru Fisheries Research Station (MFRS) of Kyoto University and stocked in a broodstock tank ( $4 \mathrm{~m}$ in diameter, $30 \mathrm{~m}^{3}$ of sea water). Mean \pm S.D. standard length $\left(L_{\mathrm{S}}\right)$ of sub-sampled males $(\mathrm{n}=17)$ and females $(\mathrm{n}=13)$ were $100.8 \pm$ $6.8 \mathrm{~mm}$ and $101.1 \pm 8.9 \mathrm{~mm}$, and their gonado-somatic index $\left(I_{\mathrm{G}}=100 \times\right.$ (gonad weight $) \times\left(L_{\mathrm{s}}\right)^{-1}$ ) were $1.50 \pm 1.24$ and $1.26 \pm 0.99$, respectively. Filtered seawater was provided in the broodstock tank. They were fed with c. $100 \mathrm{~g}$ of defrosted krill twice

100 daily until satiation. First spawning was confirmed at $20.2^{\circ} \mathrm{C}$ on 13 June. Spawning

101 continued until mid August. The highest number of eggs spawned per day was 350,000 recorded on 25 July. 
104 production: c. 44,000 eggs were spawned under natural temperature $\left(21.8^{\circ} \mathrm{C}\right)$ and

105 sub-samples of c. 11,000 floating eggs were placed into each of two black 500-1

106 polyethylene tanks (Tank 1 and Tank 2). Water was exchanged at a rate of $70 \mathrm{l} \mathrm{h}^{-1}$ with

107 filtered seawater at $22.5^{\circ} \mathrm{C}$ and air was provided at a rate of $600 \mathrm{ml} \mathrm{min}{ }^{-1}$. Hatching

108 was confirmed at 0700 hours on 11 July. Rotifers Brachionus plicatilis Müller were fed

109 with a density of 3 ind. $\mathrm{ml}^{-1}$ in the afternoon of the $1^{\text {st }}$ day post hatch (dph), and with a

110 density of 5 ind. $\mathrm{ml}^{-1}$ at 0700 and 1400 hours thereafter until $20 \mathrm{dph}$. Defrosted green

111 algae Nannochloropsis sp. was added to each tank $20 \mathrm{ml}$ at 0800 and $10 \mathrm{ml}$ at 1500

112 hours to adjust the density to 40,000 cell $\mathrm{ml}^{-1}$. Artemia sp. nauplii at $0.1-0.3$ ind. $\mathrm{ml}^{-1}$

113 enriched with nutritional supplement (Marine Gross, Nisshin Marinetech, Japan) were

114 fed from 20 dph until the end of experiment. Three to 10 individuals were sample from

115 both tanks daily until $15 \mathrm{dph}$, and at $2-5$ days intervals thereafter for the measurement

116 of $L_{\mathrm{s}}$. Fish were raised at natural temperature ranging from 21.3 to $25.1^{\circ} \mathrm{C}\left(23.2 \pm 1.0^{\circ}\right.$

117 C, mean \pm S.D. $)$ for the first 30 days, then 24.4 to $27.9^{\circ} \mathrm{C}\left(26.7 \pm 1.1^{\circ} \mathrm{C}\right)$ up to $50 \mathrm{dph}$.

MEASUREMENTS OF BEHAVIOURAL ONTOGENY

Cruise and burst swimming speeds were measured every five days starting on 10

122 dph as previously described by Masuda et al. (2002). In this method, a single fish was

123 transferred to a glass container (10-30 cm diameter depending on the size of fish)

124 covered with a black vinyl sheet on its wall and the movement of fish was recorded from above using a video camera (DCR-HC96, Sony, Tokyo, Japan). After recording for 
$12690 \mathrm{~s}$ without disturbance, the fish was startled by sound stimuli to elicit burst response.

127 Consistent sound stimuli were produced using a pendulum (a $10 \mathrm{~g}$ of steel nut hung by a 128 string) that was released from a distance of $17 \mathrm{~cm}$ from the container wall. Preliminary 129 observation revealed that visual stimuli such as casting a shadow or flashing a camera 130 strobe did not induce consistent responses and that a larva did not seem to visually 131 recognize a predator such as jellyfish until sensing the water current made by a jellyfish.

132 Sound stimuli were provided three times at 10-s intervals. This procedure was repeated 133 for 10 individuals. Cruise swimming speed was measured from $10 \mathrm{~s}$ of recording before 134 providing the sound stimulus by tracing the movement of the fish using a flexible ruler on a TV monitor. Burst swimming speed was measured only when the fish made a burst

136 start in response to the sound stimulus, and the largest value among the three trials was 137 used for further analysis. The burst swimming speed was defined as the movement in $1380.13 \mathrm{~s}$ corresponding to four frames of the video recording. The distance was divided by 139 its standard length $\left(L_{\mathrm{S}}\right)$ to express speed as $L_{\mathrm{S}} \mathrm{s}^{-1}$. Responsiveness, defined as the 140 percentage of obvious burst swimming responses against the provided stimuli, was also 141 measured at each date of measurement.

142 Escape performance exposed to jellyfish was visually observed using a method

143 previously reported by Nakayama et al. (2003) and Masuda (2006). Moon jellyfish 144 Aurelia aurita were collected off the MFRS by SCUBA diving. They were kept in two 145 500-l tanks and were used within 1 week after collection. Three actively pulsating $A$. 146 aurita (mean \pm S.D. bell diameter $=82.8 \pm 7.5 \mathrm{~mm}$ ) were put in a 10 -l plastic container.

147 A larger tank made it impossible to follow the movement of the smallest larva and thus 
148 this size of container was used. A larva of E. japonicus was gently put in this container,

149 and then observations were conducted to measure how long it took for the fish to be

150 captured by A. aurita. The observation was conducted for $5 \mathrm{~min}$, and if the fish was not eaten, it was removed and was replaced by another individual. Ten trials were conducted

152 every 5 days starting from $10 \mathrm{dph}$ up to $40 \mathrm{dph}$ (i.e. 70 individuals in total). Same

153 individuals of $A$. aurita were used throughout the replicates on each day, after which

154 they were released in the sea.

155 Behaviour in rearing tanks was also recorded via a video camera as described by

156 Masuda et al. (2003) starting on 20 dph with 3-5 days interval up to $50 \mathrm{dph}$. Two

157 semicircular reflective panels were put on the tank bottom c. 5 min prior to recording to

158 produce a clear image contrast. Focus of the video camera was locked at the layer with

159 highest density of larvae, and video analysis was conducted only on well-focused

160 individuals to capture behaviour of fish swimming in nearly two dimensions. Recording

161 was started at 1500 hours and lasted 5 min each day. Water and aeration was stopped

162 while video recording to minimize the effect of current on behaviour.

163 Three parameters of schooling were defined for video analysis: separation angle

164 (SA), distance to the nearest neighbour $\left(D_{\mathrm{NN}}\right)$ and separation swimming index $\left(I_{\mathrm{SS}}\right)$ (Fig.

165 1). SA and $D_{\mathrm{NN}}$ were criteria of parallel orientation and aggregation, respectively, and 166 were calculated on a still frame (Masuda et al., 2003). A fish close to the centre of the 167 video frame was focused on (focal fish), and then the fish closest to the focal fish was 168 defined as the neighbouring fish. The angle between the body axis of the focal fish and 169 the neighbouring fish was measured on the TV monitor using a protractor and was 
170 defined as the SA. On the same frame, three other individuals close to the focal fish

171 were selected then the distance between each fish to the closest individual from each

172 was measured by a ruler. The average of these five measurements was defined as the

$173 D_{\mathrm{NN}}$ of this frame. SA and $D_{\mathrm{NN}}$ were sampled from 30 frames each separated with a 20-s

174 interval. SA, ranging from $0^{\circ}$ to $180^{\circ}$, was expected to be $90^{\circ}$ when fish were located in

175 a random direction and was expected to decrease as they developed a parallel

176 orientation. $D_{\mathrm{NN}}$ was also expected to decrease as fish aggregated. $D_{\mathrm{NN}}$ was divided by

$177 \quad L_{s}$ to facilitate the comparison among different size groups.

178 Iss was analysed from the same video frames as SA and $D_{\mathrm{NN}}$ measurements with

179 the addition of frames $1 \mathrm{~s}$ after these (Fig. 1b). Iss reflects the tendency of parallel

180 swimming that is typical in the early stage of schooling (Masuda et al., 2003). For the

181 measurement, vectors of the focal fish and the neighbouring fish were defined as

182 movement in a 1-s interval. Then the neighbouring fish vector was moved so that its

183 starting point overlaps with that of the focal fish, and the distance of the endings of two

184 vectors was divided by the average length of the two vectors. Iss ranges from 0 to 2 and

185 it is expected to be 1.49 when two neighbouring individuals moved in random

186 directions at random speeds according to the simulation by Nakayama et al. (2007).

187 Routine swimming speed was also measured from video recordings in rearing tanks.

188 The movement of the focal fish in each video frame was traced for $1 \mathrm{~s}$ on a TV monitor.

189 The body length of the focal fish was measured on the TV monitor, and the routine

190 speed was expressed as $L_{\mathrm{S}} \mathrm{s}^{-1}$. 
192

193

194

195

196

197

198

199

200

201

202

203

204

205

206

207

208

209

210

211

212

213

\section{STATISTICAL ANALYSIS}

For the inter- and intraspecific comparisons, swimming speed data of E. japonicus was divided into three size groups as pre-flexion $(3.7-10 \mathrm{~mm})$, post-flexion $(10-21$ $\mathrm{mm})$ and metamorphosing (21-33 mm) larvae based on the criteria detailed in Fukuhara (1983). Cruise and burst swimming speeds were compared among these three different size groups using the Kruskal-Wallis test followed by the Dunn's test (Zar, 1996). Swimming speeds of E. japonicus were then compared to those in Trachurus japonicus and Scomber japonicus measured using the same methods (Masuda, 2006). Responsiveness was compared among different size groups and species in the same manner. In the analysis of survival against $A$. aurita predation, the Kruskal-Wallis test followed by the Dunn's test were applied to compare different age (and size) of $E$. japonicus larvae. The parameters of schooling behaviour were measured separately in duplicated tanks, log transformed to improve the homogeneity of variance, and were compared among different age groups in each tank using ANOVA followed by the Tukey's test after a Bonferroni correction. SA and $I_{\mathrm{Ss}}$ in each group were also compared to $90^{\circ}$ and 1.49 , respectively, by t-test. All calculations for the statistical analysis were conducted using JMP ver. 5.0.1J software (SAS Institute, Cary, NC, USA) except for the Dunn’s test (Zar, 1996). 
214 Diameters of E. japonicus eggs were $1.25 \pm 0.07$ and $0.64 \pm 0.03 \mathrm{~mm}$ in long and

215 short axis, respectively $(n=11)$ (Fig. 2). Mean notochord length of hatched larvae was

$2162.80 \pm 0.06 \mathrm{~mm}$. Pigmentation of the retina was first confirmed in the evening of 1 day

217 post hatch (dph) and all larvae had pigmented eyes on $2 \mathrm{dph}$. They attained $5.9 \mathrm{~mm}$ on

$21810 \mathrm{dph}, 11.0 \mathrm{~mm}$ on $20 \mathrm{dph}, 21.5 \mathrm{~mm}$ on $30 \mathrm{dph}, 28.3 \mathrm{~mm}$ on $40 \mathrm{dph}$ and $36.5 \mathrm{~mm}$ on

21950 dph (Fig. 2). The growth of E. japonicus was fitted with an exponential curve as

220 follows: $L_{\mathrm{S}}=3.37 \times e^{0.0542 \mathrm{dph}}(\mathrm{R}=0.963)$.

221 Cruise swimming speed of E. japonicus showed allometric development showing

$2220.5-3 L_{S} \mathrm{~s}^{-1}$ in the larval (<21 mm LS) stage but they had a much higher value of $2-7$

$223 L_{\mathrm{S} \mathrm{S}}{ }^{-1}$ at the metamorphosing stage. Cruise speed in the metamorphosing stage of $E$.

224 japonicus was higher than values in the larval stage (Dunn's test, $P<0.05$; Table I).

225 Cruise speed of E. japonicus in 10-21 $\mathrm{mm} L_{\mathrm{S}}$ was significantly slower than that of

226 Scomber japonicus in the same size range. Burst swimming speed also showed an

227 allometric development. Burst speed of metamorphosing E. japonicus was significantly

228 faster than smaller $(<21 \mathrm{~mm})$ individuals. Burst speeds of E. japonicus larvae were the

229 slowest among the three fish species, and were significantly slower than those of

230 Trachurus japonicus for both size ranges. Responsiveness to sound stimuli gradually

231 increased as fish grew, increasing from $43-50 \%$ in $6-11 \mathrm{~mm} L_{\mathrm{s}}$ larvae to $87-93 \%$ in

232 17-26 mm Ls larvae. Responsiveness of E. japonicus was significantly inferior to that

233 of T. japonicus for both size ranges (Table I).

234 Larvae of E. japonicus smaller than $11 \mathrm{~mm} L_{\mathrm{S}}$ were preyed upon by A. aurita in 235 150 s on average (Fig. 3). Anti-predator performance gradually improved, although 
236 three out of ten individuals were eaten even when they attained $23 \mathrm{~mm} L$ s. All ten

237 individuals survived 5-min predation trial in $26 \mathrm{~mm}$ or larger fish. Survival of E.

238 japonicus exposed to A. aurita was markedly inferior to that of T. japonicus and $S$. 239 japonicus (Masuda, 2006).

240 Separation angle (SA) gradually decreased in larvae from 15 to $25 \mathrm{~mm} L_{\mathrm{S}}$, 241 indicating that parallel orientation developed during this period (Fig. 4a). Distance to

242 the nearest neighbour $\left(D_{\mathrm{NN}}\right)$ also decreased in this period, and values for $23 \mathrm{~mm} L \mathrm{~s}$ fish 243 and larger showed an almost consistent value between 0.7 and $1.0 L_{\mathrm{s}}$ (Fig. 4b).

244 Decrease of the separation swimming index (ISs) was also remarkable between 15 and $24525 \mathrm{~mm} L_{\mathrm{S}}$ (Fig. 4c). SAs were significantly smaller than $90^{\circ}$ for all fish in the $17 \mathrm{~mm} L_{\mathrm{S}}$ 246 size group and larger ( $t$-test, $P<0.05$; Fig. 4a). $I_{\mathrm{SS}}$ were also smaller than 1.49 for all 247 groups at $17 \mathrm{~mm} L \mathrm{~s}$ and larger ( $t$-test , $P<0.05$; Fig. 4c). Average routine swimming speed in rearing tanks showed an allometric development from $1.6 \mathrm{LS} \mathrm{s}^{-1}$ on $20 \mathrm{dph}(11$ $\left.\mathrm{mm} L_{\mathrm{s}}\right)$ to $5.7 L_{\mathrm{S} \mathrm{s}} \mathrm{s}^{-1}$ on $38 \mathrm{dph}\left(28 \mathrm{~mm} L_{\mathrm{s}}\right)$ (Fig. $\left.4 \mathrm{~d}\right)$.

\section{DISCUSSION}

252

In rearing tanks, the growth of E. japonicus, which attained $28.3 \mathrm{~mm} L_{\mathrm{S}}$ in $40 \mathrm{dph}$, was similar to that reported for wild specimens estimated from otolith growth increments, i.e., attaining c. $30 \mathrm{~mm} L_{\mathrm{s}}$ in $40 \mathrm{dph}$ (Takahashi et al. 2001) or mean growth rates of $0.58 \mathrm{~mm} \mathrm{~d}^{-1}$ (Takasuka et al. 2004) or $0.60 \mathrm{~mm} \mathrm{~d}^{-1}$ (Hwang et al. 2006). The similarity of growth to wild specimens suggests a healthy condition for hatchery-reared 
258 larvae in the present study. Interspecific comparison revealed that the daily specific

259 growth rate of E. japonicus was intermediate between T. japonicus and S. japonicus (Fig.

260 1). The body form of E. japonicus is relatively elongate compared to T. japonicus and $S$.

261 japonicus. Therefore growth of body mass in E. japonicus would be lower than was

262 expressed in $L_{\mathrm{s}}$.

263 A single individual was observed in a limited space for the measurement of cruise

264 swimming, burst swimming, and predation by jellyfish in this study. This method can

make use of a limited number of materials and also facilitate comparison among

266 different species of fish larvae reared under different conditions. The drawback is the

267 potential stress on experimental animals. However, fish larvae usually accepted prey

268 items in the small container immediately after transfer, thus indicating that the impact of

269 stress on their behaviour may have been minimal.

$270 \quad$ Video analyses using single fish revealed that E. japonicus larvae are relatively

271 slow in both cruise and burst swimming compared to T. japonicus and S. japonicus.

272 Hunter (1972) measured the swimming speed of Engraulis mordax as $15 \mathrm{Ls} \mathrm{s}^{-1}$ of burst

273 speed and $1 L_{\mathrm{S} \mathrm{s}}{ }^{-1}$ of intermittent swimming and concluded that they are relatively slow

274 swimmers. Fuiman et al. (1999) pointed out that slower swimming species such as E.

275 mordax and Clupea harengus are typically elongate larvae that transform at larger sizes

276 than fast swimmers such as Sciaenops ocellatus, Scomber japonicus and Pagrus major

277 (Temminck \& Schlegel). A slow cruise swimming speed would reduce the chance of

278 encountering prey items and thus may induce a relatively slow growth of E. japonicus.

279 Although a slow cruise swimming speed may reduce the chance of encountering 
280 predators, slow burst speed should be disadvantageous in avoiding predators once they

281 are encountered (Fuiman \& Magurran, 1994).

282 Average routine swimming speed in rearing tanks gradually increased and the trend corresponded well with that of the cruise swimming speed measured on a single individual in an experimental container. O’Connell (1981) described that the number of red fibers in trunk musculature increased from 2-3 layers at $16 \mathrm{~mm} L_{\mathrm{S}}$ to $7-8$ layers at $26 \mathrm{~mm} L_{\mathrm{s}}$ in Engraulis mordax. Similar development of red muscle in E. japonicus is likely to have enabled the improvement of cruise and routine swimming observed in the present work. Swimming speed measured in still water, however, tends to be slower than that measured in a chamber with current or in the open ocean (Clark et al., 2005; Leis et al., 2006). Therefore caution should be used when applying absolute values of swimming speeds obtained in laboratory systems to ecological contexts. Scomber japonicus, and found that $18-48 \%$ of $6-13 \mathrm{~mm} L_{\mathrm{S}}$ larvae and $70-100 \%$ of 15-50 $\mathrm{mm} L_{\mathrm{S}}$ larvae responded to attacks by predators. Considering that their

297 measurement was based on the response to live predators and thus some larvae failed to respond before being eaten, the tendency of increased responsiveness in E. japonicus 299 during ontogeny was similar to that of E. mordax. 
302 fragile body surface. Müller (1984) reported that Clupea harengus larvae suffer high

303 mortality during blooms of Aurelia aurita. Capelin Mallotus villosus (Müller) larvae

304 also suffer substantial mortality by A. aurita predation (Elliott \& Leggett, 1997). Larvae

305 of E. japonicus, C. harengus and M. villosus have transparent and elongate bodies that

306 should be adapted to avoid visual predators, but may not be efficient in avoiding tactile

307 predators such as jellyfish. Baily \& Batty (1984) compared predation by A. aurita on

308 the yolk-sac larvae of cod Gadus morhua L., flounder Platichthys flesus L., plaice

309 Pleuronectes platesesa L. and C. harengus, and found that species with smaller larvae

310 (i.e., P. flesus) were more vulnerable to capture. They attributed the susceptibility of

311 small larvae to fewer reactions to encounter with $A$. aurita, which is in accordance with

312 the present work. They also suggested that smaller larvae received a higher dose of

313 toxin per unit of body weight. This high-dose susceptibility may also apply to

314 transparent and elongate-bodied larvae. Perhaps E. japonicus lack some protection from

315 nematocyst stings on their skin, which T. japonicus and S. japonicus possess. This may

316 explain why only small larvae of $T$. japonicus and $S$. japonicus were preyed upon,

317 whereas in the present work much larger E. japonicus larvae were preyed upon.

318 The first sign of schooling behavior was observed at $17 \mathrm{~mm} L_{\mathrm{S}}$ and schooling was

319 completed at $25 \mathrm{~mm} \mathrm{Ls}$. Hunter \& Coyne (1982) reported that the E. mordax begins

320 schooling at $11-15 \mathrm{~mm} \mathrm{Ls}$. This discrepancy in the timing of schooling onset between

321 the two species is unlikely to be due to interspecific differences in morphological

322 development, as both show similar morphological changes in sensory and swimming

323 organs. For example, rod cells in the retina appear at $14 \mathrm{~mm} L_{\mathrm{T}}\left(=12 L_{\mathrm{S}}\right)$ and $10 \mathrm{~mm} L_{\mathrm{S}}$ 
324 (O’Connell, 1981; Uyan et al., 2006), and guanine deposition is complete at $34 \mathrm{~mm} \mathrm{Ls}$

325 and $35 \mathrm{~mm} \mathrm{Ls}$ in E. japonicus and E. mordax, respectively (Takahashi \& Watanabe, 326 2004). Hunter \& Coyne (1982) conducted behavioural observations in rearing tanks whilst rearing water was being supplied, so that there should have been some water current in their rearing tanks. Fish larvae often show rheotaxis so that they can form school-like aggregations in moving water, which often collapses when the current is stopped (Masuda unpubl. data). Indeed Hunter \& Coyne (1982) suggested that the disturbance of changing the water and the resulting fright response induced an early onset of schooling. In any case, in contrast to most fish species that start to show schooling behaviour when they attain the juvenile stage (Masuda \& Tsukamoto, 1999), both Engraulis species start to form schools prior to metamorphosis. This may imply that the Engraulis life history strategy strongly depends on schooling behavior. $20 \mathrm{~mm}$ SL (Ohshimo, 1999), and then the supraorbital canal walls are completely ossified by $30.8 \mathrm{~mm} L_{\mathrm{T}}(=c .26 \mathrm{~mm} \mathrm{Ls}$ ) (Uyan et al., 2006) corresponding with the onset of schooling behaviour. This is in agreement with Cahn et al. (1968) who suggested that canalization of buccal lateral line facilitates the capability of detecting

341 specific water movement and thus enables parallel orientation in schooling. Ogawa 342 (1967) described E. japonicus larvae smaller than $25 \mathrm{~mm} L_{\mathrm{T}}$ (= c. $22 \mathrm{~mm} L_{\mathrm{s}}$ ) to have an immature brain form with relatively small cerebelli; this implies that the development of 344 the brain may also be required for the onset of schooling. 
346 fold $L_{\mathrm{s}}$. $D_{\mathrm{NN}}$ of Spanish mackerel Scomberomorus niphonius (Cuvier) measured using

347 the same method was about 1.2-1.5 Ls (Masuda et al., 2003) and $2.2 L_{\mathrm{S}}$ in Pacific

348 bluefin tuna Thunnus orientalis (Temminck \& Schlegel) (Torisawa et al. 2007). The

349 difference of $D_{\mathrm{NN}}$ is likely to reflect feeding strategy; piscivores like S. niphonius and T.

350 orientalis feed efficiently on highly mobile prey by expanding their search area,

351 whereas planktivores like E. japonicus larvae keep a low $D_{\mathrm{NN}}$ so that their school will

352 be less conspicuous without reducing feeding opportunities. Uyan et al. (2004)

353 suggested that the well-developed buccal lateral line system of this species is likely to

354 enable the high manoeuverability in schooling.

355 Even though E. japonicus larvae are slow swimmers and ideal prey for various

356 piscine and gelatinous predators, their populations seem relatively stable in Japanese

357 coastal waters (Masuda, 2009). This is also the case for congeners in the Mediterranean

358 Sea, where E. encrasicolus is the most dominant species in coastal waters (Sabatés et al.,

359 2003). Somarakis et al. (2004) attributed the abundance of E. encrasicolus to their high

360 fecundity. Engraulis japonicus also have a high fecundity and spawn from early spring

361 to autumn, and they mature in as short as six months (Tsuruta, 1992), which

362 compensates for its short life span (Kawasaki, 1980). This reproductive advantage may

363 allow the E. japonicus population to persist even with high predation pressure by

364 jellyfish as well as fishing pressure. This is in contrast to the Sardinops melanostictus in

365 which maturation requires one or two years and spawning usually occurs during limited

366 time of year at specific sites (Morimoto, 2003).

367 Engraulis japonicus larvae are likely to be preyed upon by both piscine and 
gelatinous predators. Reductions of piscine predators caused by overfishing may work advantageously to the population of E. japonicus at least temporarily. Blooms of jellyfish, however, threaten E. japonicus larvae. The threat is even more serious as the trend of the period of jellyfish blooms extends due to the reduced quality of coastal waters as well as the global warming trend (Purcell et al., 2007). Survival of E. japonicus larvae exposed to predators under various conditions such as elevated temperature and turbidity requires further research.

Rotifers required for rearing E. japonicus were kindly provided by Notojima

Walsh, C. Brown and two anonymous referees for constructive comments on the manuscript. This study was supported by a Grant-in-Aid from Japan Society for the Promotion of Science, STOPJELLY Project from the Agriculture, Forestry and Fisheries

Research Council, Japan, and Food and Function Research Center, Nippon Suisan

Kaisha, Ltd. The experiments were conducted in accordance with the guidelines of

Regulation on Animal Experimentation at Kyoto University.

\section{References}

387 Bailey, K. M. \& Batty, R. S. (1984). Laboratory study of predation by Aurelia aurita on 388 larvae of cod, flounder, plaice and herring: development and vulnerability to capture. 
390 Blaxter, J. H. S. (1985). The herring: a successful species? Canadian Journal of

$391 \quad$ Fisheries and Aquatic Sciences 42, 21-30.

392 Castro, L. R., Salinas, G. R. \& Hernández, E. H. (2000). Environmental influences on 393 winter spawning of the anchoveta Engraulis ringens off central Chile. Marine 394 Ecology Progress Series 197, 247-258.

395 Cahn, P. H., Shaw, E. \& Atz, E. H. (1968). Lateral-line histology as related to the 396 development of schooling in the atherinid fish, Menidia. Bulletin of Marine Science $397 \quad \mathbf{1 8}, 660-670$.

398 Chavez, F. P., Ryan, J., Lluch-Cota, S. E. \& Ñiquen C, M. (2003). From anchovies to 399 sardines and back: multidecadal change in the Pacific Ocean. Science 299, 217-221.

400 Clark, D. L., Leis, J. M., Hay, A. C. \& Trnski, T. (2005). Swimming ontogeny of larvae 401 of four temperate marine fishes. Marine Ecology Progress Series 292, 287-300.

402 Elliot, J. K. \& Leggett, W. C. (1997). Influence of temperature on size-dependent 403 predation by a fish (Gasterosteus aculeatus) and a jellyfish (Aurelia aurita) on larval 404 capelin (Mallotus villosus). Canadian Journal of Fisheries and Aquatic Sciences 54, $405 \quad 2759-2766$.

406 Folkvord, A. \& Hunter J. R. (1986). Size-specific vulnerability of northern anchovy, 407 Engraulis mordax, larvae to predation by fishes. Fishery Bulletin 84, 859-869.

408 Fuiman, L. A. \& Magurran, A. E. (1994). Development of predator defences in fishes. 409 Reviews in Fish Biology and Fisheries 4, 145-183.

410 Fuiman, L. A., Smith, M. E. \& Malley, V. N. (1999). Ontogeny of routine swimming 411 speed and startle responses in red drum, with a comparison of responses to acoustic 
413 Fukuhara, O. (1983). Development and growth of laboratory reared Engraulis japonica 414 (Houttuyn) larvae. Journal of Fish Biology 23, 641-652.

415 Hunter J. R. (1972). Swimming and feeding behavior of larval anchovy Engraulis 416 mordax. Fishery Bulletin 70, 821-838.

417 Hunter, J. R. (1980). The feeding behavior and ecology of marine fish larvae. In Fish 418 Behavior and its Use in the Capture and Culture of Fishes (Bardach, J. E., Magnuson, 419 J. J., May, R. C. \& Reinhart, J. M. eds), pp. 287-330. Manila: International Center for 420 Living Aquatic Resources Management.

421 Hunter, J. R. \& Coyne, K. M. (1982). The onset of schooling in northern anchovy larvae, 422 Engraulis mordax. CalCOFI Report 23, 246-251.

423 Hwang, S.-D., Song, M.-H., Lee, T.-W., McFarlane, G. A. \& King, J. R. (2006). Growth 424 of larval Pacific anchovy Engraulis japonicus in the Yellow Sea as indicated by 425 otolith microstructure analysis. Journal of Fish Biology 69, 1756-1769.

426 Kawasaki, T. (1980). Fundamental relations among the selections of life history in the 427 marine teleosts. Bulletin of the Japanese Society of Scientific Fisheries 46, 289-293.

428 Kawasaki, T. (1992). Mechanisms governing fluctuations in pelagic fish populations. 429 South African Journal of Marine Science 12, 873-879.

430 Leis, J. M., Hay, A. C., Clark, D. L., Chen, I. S. \& Shao, K. T. (2006). Behavioral 431 ontogeny in larvae and early juveniles of the giant trevally (Caranx ignobilis) 432 (Pisces: Carangidae). Fishery Bulletin 104, 401-414. 
434 Trachurus japonicus larvae and juveniles: patchiness formation, swimming capability, 435 and interaction with jellyfish. Fisheries Science 72, 1225-1235.

436 Masuda, R. (2009). Behavioral ontogeny of marine pelagic fishes with the implications 437 for the sustainable management of fisheries resources. Aqua-BioScience Monograph 438 $2(2), 1-56$.

Masuda, R. \& Tsukamoto K. (1999). School formation and concurrent developmental changes in carangid fish with reference to dietary conditions. Environmental Biology 441 of Fishes 56: 243-252.

442 Masuda, R., Shoji, J., Aoyama, M. \& Tanaka, M. (2002). Chub mackerel larvae fed fish 443 larvae can swim faster than those fed rotifers and Artemia nauplii. Fisheries Science $444 \quad 68,320-324$.

Masuda, R., Shoji, J., Nakayama, S. \& Tanaka, M. (2003). Development of schooling 446 behavior in Spanish mackerel Scomberomorus niphonius during early ontogeny. $447 \quad$ Fisheries Science 69, 772-776.

448 Matsuda, H., Wada, T., Takeuchi, Y. \& Matsumiya, Y. (1991). Alternative models for 449 species replacement of pelagic fishes. Research on Population Ecology 33, 41-56.

Morimoto, H. (2003). Age and growth of Japanese sardine Sardinops melanostictus in 451 Tosa Bay, south-western Japan during a period of declining stock size. Fisheries 452 Science 69, 745-754.

453 Müller, H. (1984). Reduction of a larval herring population by jellyfish predator. $454 \quad$ Science 224, 621-622.

455 Nakayama, S., Masuda, R., Takeuchi, T. \& Tanaka, M. (2003). Effects of highly 
456 unsaturated fatty acids on escape ability from moon jellyfish Aurelia aurita in red sea 457 bream Pagrus major larvae. Fisheries Science 69, 903-909.

458 Nakayama, S., Masuda, R. \& Tanaka, M. (2007). Onsets of schooling behavior and 459 social transmission in chub mackerel Scomber japonicus. Behavioral Ecology and $460 \quad$ Sociobiology 61, 1383-1390.

461 O’Connell, C. P. (1981). Development of organ systems in the northern anchovy, 462 Engraulis mordax, and other teleosts. American Zoologist 21, 429-446.

463 Ogawa, Y. (1967). Morphological transition of the brain components of anchovy with 464 their body-growth. Bulletin of the Japanese Society of Scientific Fisheries 33, $465 \quad 531-538$.

466 Ohshimo, S. (1999). Development of the cephalic lateral line nerves of the Japanese 467 anchovy, Engraulis japonicus. Bulletin of Seikai National Fisheries Research $468 \quad$ Institute 77, 1-10.

469 Purcell, J. E., Uye, S. \& Lo, W.-T. (2007). Anthropogenic causes of jellyfish blooms and 470 their direct consequences for humans: a review. Marine Ecology Progress Series 350, $471 \quad 153-174$.

472 Sabatés, A., Zabala, M. \& García-Rubies, A. (2003). Larval fish communities in the 473 Medes Islands Marine Reserve (North-west Mediterranean). Journal of Plankton $474 \quad$ Research 25, 1035-1046.

475 Shiganova, T. A. (1998). Invasion of the Black Sea by the ctenophore Mnemiopsis leidyi 476 and recent changes in pelagic community structure. Fisheries Oceanography 7, 477 305-310. 
478

479

480

481

482

483

484

485

486

487

488

489

490

491

492

493

494

495

496

497

498

499

Somarakis, S., Palomera, I., Garcia, A., Quintanilla, L., Koutsikopoulos, C., Uriarte, A. \& Motos, L. (2004). Daily egg production of anchovy in European waters. ICES Journal of Marine Science 61, 944-958.

Takahashi, M. \& Watanabe, Y. (2004). Staging larval and early juvenile Japanese anchovy based on the degree of guanine deposition. Journal of Fish Biology 64, $262-267$.

Takahashi, M. \& Watanabe, Y. (2005). Effects of temperature and food availability on growth rate during late stage of Japanese anchovy (Engraulis japonicus) in the Kuroshio-Oyashio transition region. Fisheries Oceanography 14, 223-235.

Takahashi, M., Watanabe, Y., Kinoshita, T. \& Watanabe, C. (2001). Growth of larval and early juvenile Japanese anchovy, Engraulis japonicus, in the Kuroshio-Oyashio transition region. Fisheries Oceanography 10, 235-247.

Takasuka, A., Aoki, I. \& Mitani, I. (2004). Three synergistic growth-related mechanisms in the short-term survival of larval Japanese anchovy Engraulis japonicus in Sagami Bay. Marine Ecology Progress Series 270, 217-228.

Takasuka, A., Oozeki, Y. \& Aoki, I. (2007). Optimal growth temperature hypothesis: Why do anchovy flourish and sardine collapse or vice versa under the same ocean regime? Canadian Journal of Fisheries and Aquatic Sciences 64, 768-776.

Takasuka, A., Oozeki, Y. \& Kubota, H. (2008). Multi-species regime shifts reflected in spawning temperature optima of small pelagic fish in the western North Pacific. Marine Ecology Progress Series 360, 211-217.

Torisawa, S., Takagi, T., Fukuda, H., Ishibashi, Y., Sawada, Y., Okada, T., Miyashita, S., 
500 Suzuki, K. \& Yamane, T. (2007). Schooling behaviour and retinomotor response of

501 juvenile Pacific bluefin tuna Thunnus orientalis under different light intensities.

$502 \quad$ Journal of Fish Biology 71, 411-420.

503 Tsuruta, Y. (1992). Reproduction in the Japanese anchovy (Engraulis japonica) as

504 related to population fluctuation. Bulletin of the National Research Institute of $505 \quad$ Fisheries Engineering 13, 129-168.

506 Uyan, S., Kawamura, G., Vazquez Archdale, M. (2004). Morphology of the sense organs 507 of anchovy Engraulis japonicus. Fisheries Science 72, 540-545.

508 Uyan, S., Kawamura, G., Vazquez Archdale, M. (2006). Morphology of the sense organs 509 in larval anchovy Engraulis japonicus caught by midwater trawl. Aquaculture $510 \quad$ Science 54, 275-282.

511 Zar, J.H. (1996). Biostatistical Analysis, $3^{\text {rd }}$ edn. Englewood Cliffs, NJ; Prentice Hall. 
Table I. Comparison of cruise swimming speed, burst swimming speed and responsiveness among different size groups, and among the three different fish species

Cruise Speed $\left(L \mathrm{~s} \mathrm{~s}^{-1}\right)$

Engraulis japonicus $1.42 \pm 0.74(23) \mathrm{b} \quad 1.80 \pm 0.99$ (19) b $3.85 \pm 1.24(17) \mathrm{a}$

Trachurus japonicus $1.75 \pm 1.15$ (95) $\quad 1.65 \pm 0.99(55)$

Scomber japonicus $1.56 \pm 0.72(23) \quad 3.20 \pm 1.88(47) *$

Burst Speed $\left(L_{\mathrm{S} \mathrm{s}}{ }^{-1}\right)$

Engraulis japonicus $\quad 6.08 \pm 4.14(17) \mathrm{b} \quad 9.50 \pm 6.89$ (16) b $\quad 28.4 \pm 12.1$ (17) a

Trachurus japonicus $18.7 \pm 9.3(87) \mathrm{b}^{*} \quad 22.7 \pm 7.10(55) \mathrm{a}^{*}$

Scomber japonicus $8.03 \pm 3.53(12) \mathrm{b} \quad 15.7 \pm 5.58$ (35) a*

Responsiveness (\%)

Engraulis japonicus $\quad 50.1 \pm 40.0(23) \mathrm{b} \quad 64.9 \pm 37.6(19) \mathrm{ab} \quad 88.2 \pm 26.2$ (17) a

Trachurus japonicus $79.3 \pm 32.3(95) \mathrm{b}^{*} \quad 97.6 \pm 8.7(55) \mathrm{a}^{*}$

Scomber japonicus $\quad 27.5 \pm 31.2(23) \mathrm{b} \quad 66.7 \pm 42.8(47) \mathrm{a}$ 
Values with different letters are significantly different among size groups in the same species, and values with an asterisk are significantly larger than that of Engraulis japonicus in the same size group (Dunn's test, $P<0.05$ ). 
Figure captions

Fig. 1. (a) Measurements of separation angle (SA) and the distance to the nearest neighbour $\left(D_{\mathrm{NN}}\right) . l_{1}$ is the $D_{\mathrm{NN}}$ for the individual F, and so is $l_{2}$ for the individuals $\mathrm{N}_{1}$ and $\mathrm{N}_{2}$. Average of $l_{1}, l_{2}, l_{2}, l_{3}$ and $l_{4}$ will be the $D_{\mathrm{NN}}$ for this frame. (b) Measurement of the separation swimming index $\left(I_{\mathrm{SS}}\right)$. Swimming trajectories of neighbouring individuals were expressed as vectors, and the distance between the two vectors $d$ divided by the average length of $v_{1}$ and $v_{2}$ was defined as $I_{\mathrm{SS}}$.

Fig. 2. Growth (mean \pm S.D.) of Engraulis japonicus (black circles: present work) together with Scomber japonicus (triangles) and Trachurus japonicus (squares) (Masuda, 2006). Data were fitted to exponential curves.

Fig. 3. Developmental changes of avoidance of Aurelia aurita by Engraulis japonicus (present work), Scomber japonicus and Trachurus japonicus (Masuda, 2006). Symbols are the same as in Fig. 2. Values without sharing an alphabet letter differ significantly (Dunn's test, $P<0.05$ ).

Fig. 4. Developmental changes of three schooling parameter as (a) separation angle, (b) distance to the nearest neighbour, and (c) separation swimming index and (d) development of routine swimming speed in rearing tanks. Open circles (lower case) and closed circles (upper case) represent tank 1 and tank 2, respectively. Values without sharing an alphabet letter differ significantly (Tukey's test, $P<$ $0.05)$. 
(a)

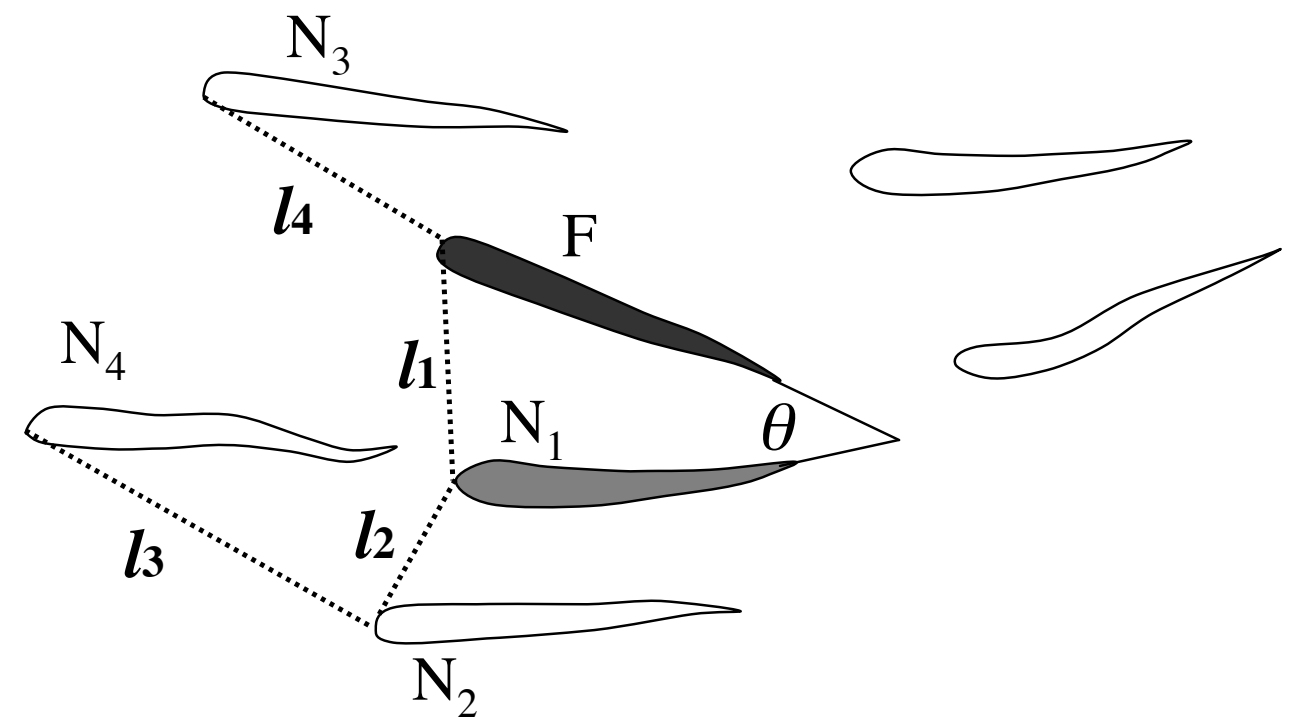

(b)

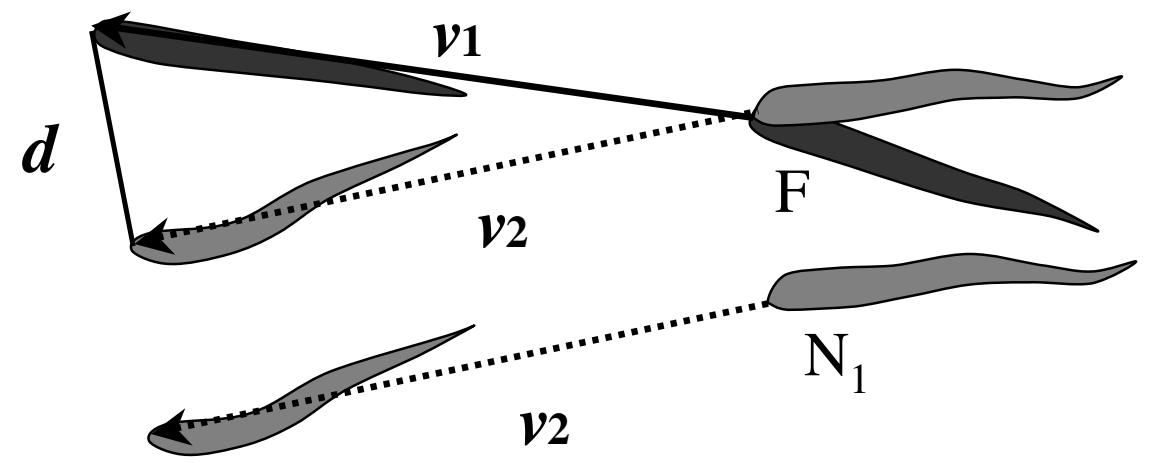

Fig. 1. 


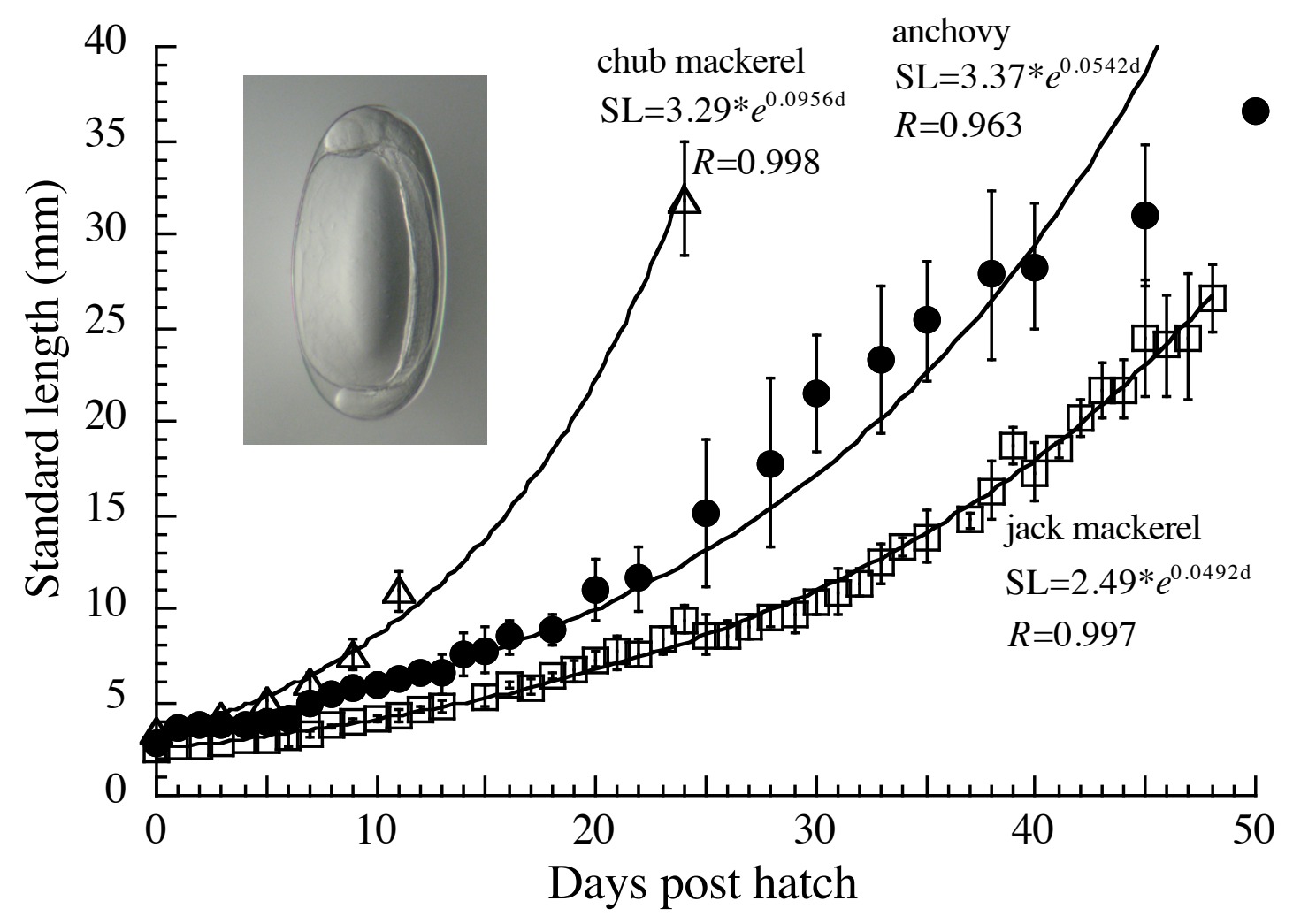

Fig. 2. 


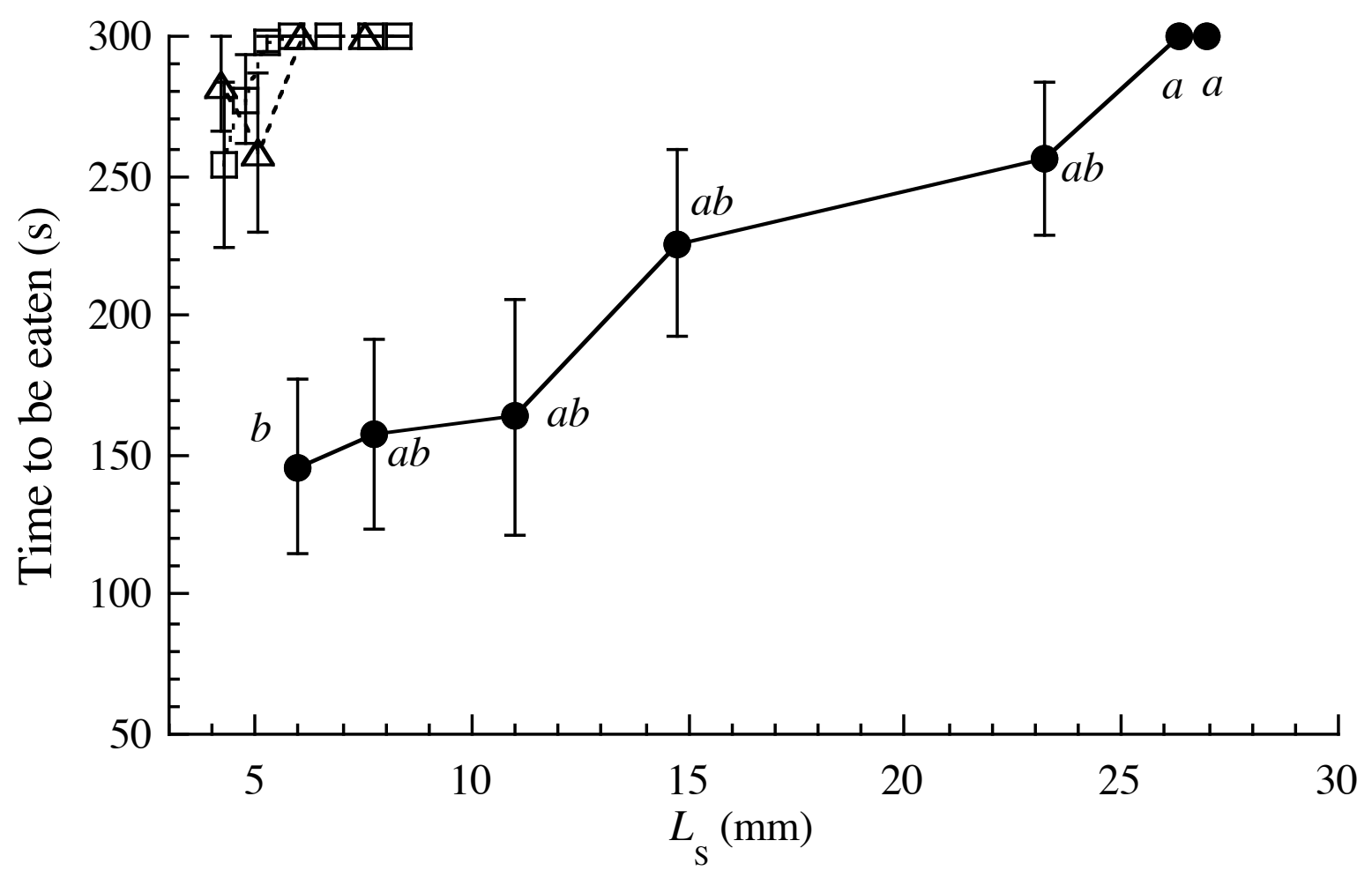

Fig. 3. 

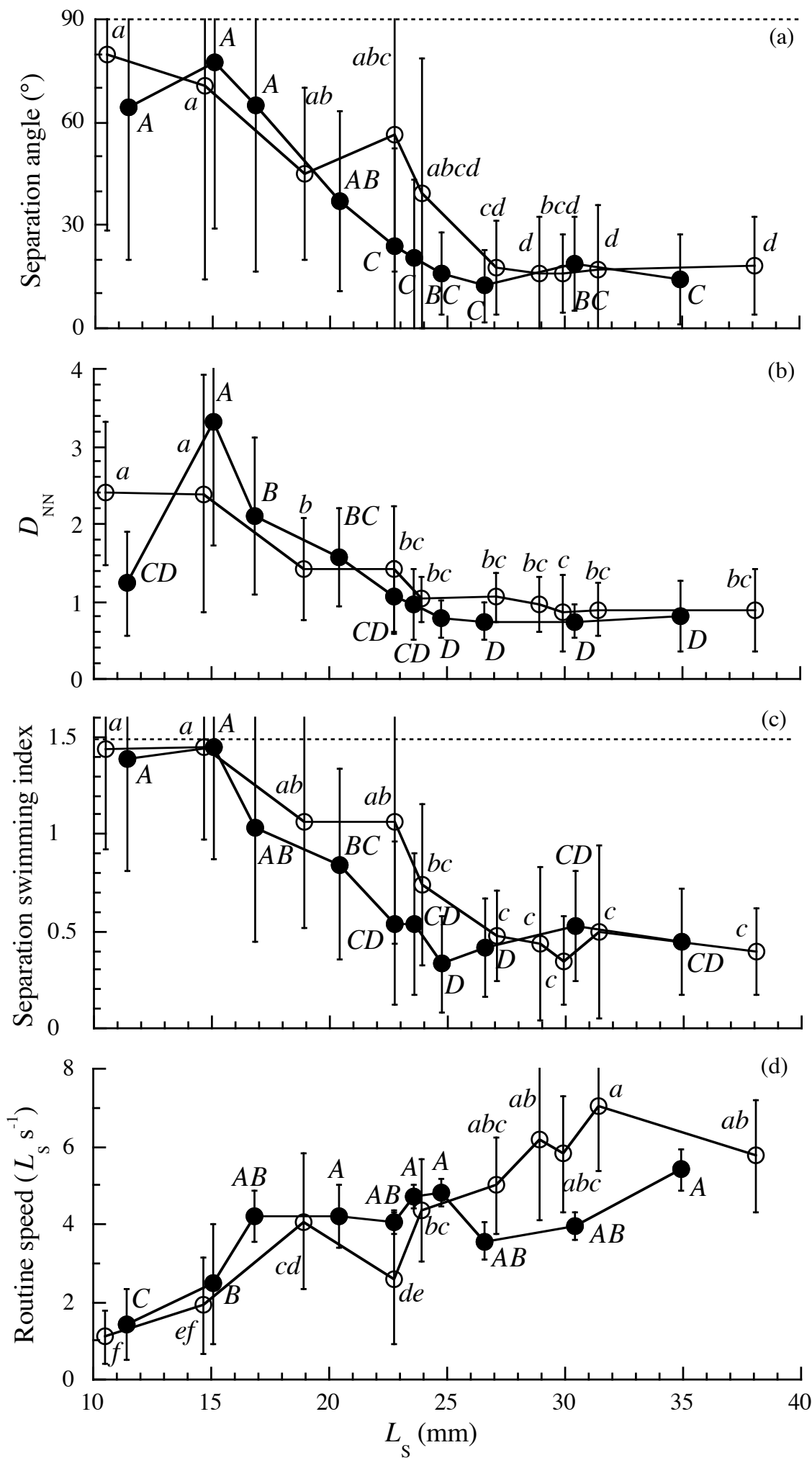

Fig. 4. 